\title{
The Burden and Management of Dyslipidemia: Practical Issues
}

\author{
Alyssa B. Schultz, PhD, Chin-Yu Chen, PhD, Wayne N. Burton, MD, ${ }^{2}$ and Dee W. Edington, PhD ${ }^{1}$
}

\begin{abstract}
The objective of this study is to describe briefly the burden of dyslipidemia, and to discuss and present strategies for health professionals to improve dyslipidemia management, based on a review of selected literature focusing on interventions for dyslipidemia treatment adherence. Despite the availability of effective lifestyle and pharmaceutical therapies for dyslipidemias, they continue to present a significant economic burden in the United States. Adherence to evidence-based guidelines for the treatment of dyslipidemias is unsatisfactory. The reasons for medication nonadherence are complex and specific to each patient. The lack of progress in achieving optimal lipid targets is caused by many factors: patient (medication adherence, cost of medication, literacy), medication (adverse effects, complexity of regimen), provider (lack of adherence to evidence-based practice guidelines, poor communication), and the US healthcare system (being focused on acute care rather than prevention, lack of continuity of care, general lack of use of an electronic health record). Combined interventions that target each part of the system have been effective in improving treatment adherence and achieving lipid goals. Patients, providers, pharmacists, and employers all play a role in management of dyslipidemia. No single approach will solve the complex issue of improving dyslipidemia management. The required lifestyle changes are known and effective medications are available. The challenge is for all interested parties-including nurses, nurse practitioners, doctors, pharmacists, other health care professionals, employers, and health plans-to help patients achieve behavioral changes. (Population Health Management 2012;15:302-308)
\end{abstract}

\section{Introduction}

D YSLIPIDEMIAS ARE ASSOCIATED WITH NUMEROUS MEDICAL CONDITIONS including heart disease, peripheral vascular disease, and stroke. ${ }^{1,2}$ The health and economic outcomes associated with dyslipidemias are well documented. A MEDLINE literature review in 2007 identified more than 43,000 papers about dyslipidemia, more than 700 of which focused on its economic burden. ${ }^{3}$ Cardiovascular disease is responsible for more than 800,000 deaths each year in the United States at an estimated $\$ 286$ billion in direct and indirect costs. ${ }^{4}$ About $16 \%$ of the adult US population has a total cholesterol level $\geq 240 \mathrm{mg} /$ $\mathrm{dL} ; 45 \%$ of adults have a total cholesterol level $\geq 200 \mathrm{mg} / \mathrm{dL}$. The current guidelines for optimal cholesterol levels include: low-density lipoprotein cholesterol (LDL-C) $<100 \mathrm{mg} / \mathrm{dL}$ and total cholesterol $<200 \mathrm{mg} / \mathrm{dL}^{2}$ If patients are at very high risk for coronary heart disease (CHD), an LDL-C goal of $<70 \mathrm{mg}$ / $\mathrm{dL}$ is recommended. ${ }^{5}$

The expert panel of the National Cholesterol Education Program (NCEP) recommended initiating therapeutic life- style changes if LDL-C is above goal and adding HMG-CoA reductase inhibitor (statin) and other lipid-lowering medications for patients who have not achieved LDL-C treatment goals through lifestyle modifications. ${ }^{2}$ Despite the estimate that a $10 \%$ decrease in total cholesterol levels might reduce the incidence of heart disease by $30 \%,{ }^{6}$ less than half of those who qualify receive lipid-lowering treatment for heart disease. $^{2}$ Furthermore, the Healthcare Effectiveness Data and Information Set (HEDIS) benchmarks for managed care organizations (MCOs) include 2 measures for cholesterol management. In 2009,59.2\% of commercially insured health maintenance organization patients with a diagnosis of ischemic vascular disease had achieved LDL-C levels $<100 \mathrm{mg} / \mathrm{dL}^{7}$; only $47.0 \%$ of patients with diabetes had achieved LDL-C levels $<100 \mathrm{mg} / \mathrm{dL}^{7}$

What role can health professionals play in achieving hyperlipidemia goals? A simulation study of the effects of HEDIS performance measures on different health outcomes found that if all MCOs met their hyperlipidemic targets at the median level, approximately 1.9 million myocardial

\footnotetext{
${ }^{1}$ University of Michigan Health Management Research Center, Ann Arbor, Michigan.
}

${ }^{2}$ University of Illinois at Chicago, Chicago, Illinois. 
infarctions and 0.8 million strokes could have been prevented over 10 years. $^{8}$ Although the current review should not be considered comprehensive of the entire body of literature surrounding dyslipidemia management, its purpose is to discuss and present strategies for health management professionals to help improve dyslipidemia care.

\section{Strategies}

\section{Lifestyle changes}

Several studies have demonstrated the benefits of diet and exercise in reducing LDL-C and cardiovascular events in patients with and without CHD. ${ }^{9-17}$ All adults should be encouraged to adopt a healthy lifestyle, but these factors are even more important for patients with elevated LDL-C levels. ${ }^{5}$ These dietary and lifestyle modifications include adopting healthy eating habits (limiting sugar and refined carbohydrates, and increasing fruit, vegetable, and whole grain consumption), not smoking, maintaining a healthy weight and an optimal waist circumference, and engaging in regular physical activity., ${ }^{2,18}$ If lifestyle modifications are unsuccessful in achieving optimal lipid levels, lipid-lowering therapy may be necessary. ${ }^{2,19}$

However, it appears that clinicians may be discounting the benefits of lifestyle behavior changes prior to initiating pharmaceutical treatment. In one study, $79 \%$ of study patients wanted to try changing their diet prior to starting a statin but only half reported being given that opportunity. ${ }^{20}$ Of those who had the opportunity to modify their diet, $43 \%$ felt they were not allowed sufficient time to change their behavior before being prescribed a statin. ${ }^{20}$ Categorizing patients based on risk factors into low, intermediate, and high risk can provide physicians with guidelines about which patients should attempt to make lifestyle changes prior to initiating drug therapy. ${ }^{21}$

\section{Pharmaceutical therapies}

Although clinical trials repeatedly show that statins are effective in lowering LDL-C levels, ${ }^{22-28}$ actual clinical experience does not always match these results. ${ }^{29-35}$ Medication adherence, failure to titrate to the most effective dose or medication, inadequate follow-up, disparities in screening and prescribing, and lack of patient motivation all have been hypothesized as reasons for the gap in achieving LDL-C goals between what is reported in clinical trials and actual results observed in physician medical practices. ${ }^{36-39}$

The NCEP has acknowledged ${ }^{5}$ that achieving the $<70 \mathrm{mg} / \mathrm{dL}$ LDL-C goal will be difficult for many patients, particularly using statin monotherapy. ${ }^{40}$ However, the effect and risks of combining different types of cholesterol-lowering medications (statins with bile acid sequestrants, or statins with other lipid-lowering agents) is not well understood by physicians, ${ }^{41}$ despite studies demonstrating their potential safety and efficacy. ${ }^{42-46}$

The managed care community is familiar with the poor medication adherence rates associated with many drug classes and lipid-lowering therapies in particular. ${ }^{47}$ The World Health Organization estimates an average medication adherence rate of approximately $50 \% .{ }^{48}$ Nonadherence is associated with increased hospitalizations and treatment costs as well as loss of productivity and premature death. ${ }^{49}$
Discontinuation rates among patients who initiate statin therapy range from $15 \%$ to $78 \%$ depending on the study location, sample demographics, and length of follow-up. ${ }^{50,51}$

\section{Predictors of nonadherence}

Studies have found that poor medication adherence is associated with younger patient age, female sex, fewer comorbidities, no cholesterol level monitoring after statin initiation, depression, low perceived risk of myocardial infarction, misconceptions about treatment duration, ${ }^{20,52}$ feelings about medical providers and belief in the benefit of the medication, ${ }^{53}$ number of other medications being taken, ${ }^{54}$ and prescription size. ${ }^{54,55}$ Higher co-payments also have been found to be associated with lower levels of statin adherence and prescription abandonment. ${ }^{52,56-60}$ Patients treated to a target cholesterol level are significantly more adherent to statins and have better cardiovascular outcomes than those treated by a "treat and forget" method. ${ }^{61}$

\section{Suggestions for Population Health Management}

How can health management professionals help to reduce the burden of dyslipidemia among US adults? Is the lack of progress in reducing LDL-C levels because of the patients (medication adherence issues, cost of medication), the medications (adverse effects, complexity of regimen), the providers (lack of evidence-based practice and follow-up, poor communication), or the system (focused on acute care rather than prevention, lack of continuity of care) $?^{63-65}$ The National Committee for Quality Assurance instituted a HEDIS measure for MCOs that differentiates between the management of individual patients (LCL-C goal $<100 \mathrm{mg} / \mathrm{dL}$ ) and a performance measure used to evaluate the care of a specific population of patients who have had a major CHD event (LDL-C goal $<70 \mathrm{mg} / \mathrm{dL}$ ). ${ }^{66}$ Researchers also have proposed other measures that can help MCOs to benchmark their quality of care of dyslipidemia. These include expanding the population defined in HEDIS to include more candidates for therapy, determining how many of those patients are on lipid-lowering medications, and using the appropriate LDLC goal values from the NCEP recommendations. ${ }^{67}$

\section{Providers}

Providers must stay current on the most recent evidencebased medicine guidelines for lipid management, such as the identification of those patients at risk for cardiovascular events and the use of appropriate lifestyle and medications to achieve lipid treatment goals. ${ }^{68,69}$ Only about one third of patients who receive treatment are achieving their LDL-C goal, and fewer than $20 \%$ of CHD patients are at their target LDL-C level. ${ }^{2}$ Results from other studies suggest that physicians are not titrating the dose of lipid-lowering medications to reach the optimal cholesterol goal. ${ }^{77,78}$ Providers must be held to the most current evidence-based practice guidelines for the appropriate use of statins, including cautions, contraindications, and safety monitoring of various parameters during treatment. ${ }^{71}$ Health care provider strategies to improve adherence might include limiting the number of medications prescribed for a patient when possible. ${ }^{72}$ Earlier and more frequent follow-up visits also have been shown to improve adherence to statins. ${ }^{73}$ In this regard, 
pay-for-performance initiatives have had some mixed but promising results. ${ }^{74}$ Electronic medical records also show promise in improving management of dyslipidemia. ${ }^{75,76}$

Nurses, nutritionists, and pharmacists can play an important role in a collaborative approach to dyslipidemia management. Effective nutrition education can improve blood lipid levels, ${ }^{77,78}$ while nurses and other members of the health care team can provide effective case management services to individuals, particularly those dealing with multiple risk factors for heart disease. ${ }^{79,80}$ Pharmacists are knowledgeable about medications, treatment indications, dosing, safety issues, side effects, and contraindications. They are highly accessible at the point of medication dispending and can improve medication adherence through education and face-to-face counseling. ${ }^{81}$ In some cases, pharmacist-managed clinics have been shown to improve dyslipidemia management and goal attainment compared with groups managed by primary care physicians. ${ }^{82-84}$

\section{Patients}

Patients also need better education that should include addressing their individual health literacy. Those who are knowledgeable and participate in their health care decisions have better behaviors and outcomes. ${ }^{63}$ Cardiovascular patients have been shown not only to have poor adherence to medication regimens and diet recommendations, but also poor attendance at follow-up appointments. ${ }^{85}$ One large review of statin adherence interventions found that, in general, personalized and patient-focused interventions were the most cost-effective. ${ }^{86}$ Research supports the use of techniques to improve patients' belief in their ability to follow medication regimens. ${ }^{87}$ Moreover, patients who are made aware of the potential adverse effects of medication may have appropriate expectations and increased adherence. ${ }^{88}$ In one study, LDL-C, exercise, and dietary goals were achieved by significantly more patients who received nurse-mediated care compared to patients who received only enhanced primary physician care. ${ }^{8,9}$ Preactivating patients prior to physician visits may be an important strategy. Written materials, telephone consultations, or pre-visit discussions with a care manager may enable patients to be more assertive and involved in medical care visits. ${ }^{63}$ Expecting all patient education and patient concerns to be discussed in the traditional 15-minute physician visit is a setup for failure. ${ }^{63}$ A technique called motivational interviewing may help patients resolve any ambivalence they may feel toward their prescribed treatment plan. ${ }^{90}$

Pill splitting has been promoted as a possible strategy to improve patient adherence when medication cost is a barrier. ${ }^{91-95}$ Potential problems with pill splitting include inaccurate dosing, loss of medication due to fragmentation, and patient dissatisfaction, which could lead to nonadherence. ${ }^{91,96.97}$ Technology also may be used to improve adherence. The Electronic Medication Management Assistant is a computerized medication dispenser that patients can use at home. ${ }^{98}$ It works in conjunction with an electronic medication administration record, which allows medication use to be supervised remotely by health care providers who can take action when the patient is nonadherent. Electronic caps, also known as microelectronic monitoring systems (MEMS), have been used in medication adherence research. Showing patients the results from their MEMS output and discussing the results may be effective in increasing medication adherence. ${ }^{99}$ A variety of other technologies are available to aid with medication adherence, including smart phone reminders, tracking applications, and videophone technology.

\section{Pharmacy benefit managers}

Organizations can work with their pharmacy benefit providers to ensure formulary access to the appropriate medications for dyslipidemia. ${ }^{68}$ These medications frequently have higher co-pays because of the expense and widespread use of statin drugs; however, it may be a cost-effective strategy in terms of improved adherence and effectiveness to lower copayments for selected medications for certain patients. ${ }^{100,101}$ One study demonstrated that a co-payment reduction was associated with a $7 \%$ improvement in statin adherence. ${ }^{102}$ Sokol and colleagues showed that the increased cost for medication to treat dyslipidemia was more than offset by the savings in health care cost from a reduction in hospitalization expenditures that resulted from improved adherence. ${ }^{103}$ Community-based studies utilizing pharmacists to provide patient education have been successful in improving medication adherence and clinical outcomes for patients. ${ }^{104,105}$

\section{Employers}

Employers also have a vested interest in improving dyslipidemia management for their employees. One study found that, even among executives for whom medication cost should not be a barrier to medication adherence, only $68 \%$ of statin users were adherent. ${ }^{106}$ Worksite disease management programs commonly are used to improve the health and productivity of employees. Compared with usual care, both a worksite educational program and a small monetary incentive were successful in reducing LDL-C levels among employees. ${ }^{107}$ As the frequent payers of health care costs, employers can play an important role in benefit design and selection of health plans that have proven to be better at prevention-focused care. Pharmacy benefit plan design is an important tool to improve patient treatment and adherence. A literature review has indicated that as patient medication cost sharing increases, there is a correlation with reduced medication use but greater use of medical services, as well as increased health consequences for conditions such as dyslipidemia. $^{108}$

\section{Conclusions}

A Cochrane Collaboration reviewed interventions to improve adherence to lipid-lowering medication. ${ }^{109}$ The reviewers concluded that adherence improvement interventions typically fall into one of 4 categories: simplification of drug regimen; patient information/education; intensified patient care such as reminder programs; and complex behavioral interventions such as group sessions. Results from the studies reviewed found that adherence rates changed from $-3 \%$ to $+25 \%$ as a result of the interventions. ${ }^{109} \mathrm{~A}$ combined intervention that targets both providers and patients also has been effective in increasing cholesterol goal attainment (from $35.5 \%$ of patients before to $59.8 \%$ after the intervention). ${ }^{110}$ There appears to be no single approach that will solve the complex issue of improving dyslipidemia 
management. The required lifestyle changes are known and effective medications are available. The challenge is for all interested parties-nurses, physicians, pharmacists, employers, and health plans - to encourage patients to change their behavior.

Advances in medical treatments will fail to realize their potential in reducing chronic illness unless the system can address the determinants of adherence. Access to medications is necessary but insufficient in itself for the successful treatment of dyslipidemia and other conditions. ${ }^{48}$ The easiest way to determine adherence may be for physicians to inquire in a nonjudgmental manner about how many doses are missed in the average week. ${ }^{65}$ Medication adherence has been proposed as the "sixth vital sign" in addition to standard vital signs recorded on patient visits (ie, blood pressure, pulse, respiration, temperature, and weight [or body mass index]). ${ }^{40}$ Patients who have the most difficulty staying adherent to their regimen-whether because of such factors as cost, forgetfulness, misunderstanding of the benefits or side effects, and number of pills-will benefit from the more intensive interventions mentioned in this study, such as electronic monitoring with telephone reminders.

\section{Author Disclosure Statement}

Drs. Schultz, Chen, Burton, and Edington disclosed no conflicts of interest.

\section{References}

1. American Heart Association. Why cholesterol matters. Available at: http://www.heart.org/HEARTORG/ Conditions/Cholesterol/WhyCholesterolMatters/WhyCholesterol-Matters_UCM_001212_Article.jsp. Accessed October 2011.

2. National Institutes of Health. Third Report of the National Cholesterol Education Program (NCEP). Expert panel on detection, evaluation, and treatment of high blood cholesterol in adults (Adult Treatment Panel III) final report. Circulation. 2002;106:3143-3421.

3. Smith DG. Epidemiology of dyslipidemia and economic burden on the healthcare system. Am J Manag Care 2007; 13:S68-71.

4. Roger VL, Go AS, Lloyd-Jones DM, et al. Heart disease and stroke statistics-2011 update: A report from the American Heart Association. Circulation 2011;123:e18-e209.

5. Grundy SM, Cleeman JI, Bairey Merz CN, et al. Implications of recent clinical trials for the National Cholesterol Education Program Adult Treatment Panel III Guidelines. Circulation 2004;110:227-239.

6. Centers for Disease Control and Prevention. State-specific cholesterol screening trends-United States, 1991-1999. MMWR Morb Mortal Wkly Rep 2000;49:750-755.

7. National Committee for Quality Assurance. The state of healthcare quality 2011. Available at: http://www.ncqa .org/tabid/836/Default.aspx. Accessed October 2011.

8. Eddy DM, Pawlson G, Schaaf D, et al. The potential effects of HEDIS performance measures on the quality of care. Health Affairs (Millwood) 2008;27:1429-1441.

9. Hu FB, Willett WC. Optimal diets for prevention of coronary heart disease. IAMA 2002;288:2569-2578.

10. Frantz ID Jr, Dawson EA, Ashman PL, et al. Test of effect of lipid lowering by diet on cardiovascular risk: The Minnesota Coronary Survey. Arteriosclerosis1989;9:129-135.
11. Nissen SE, Tuzcu EM, Schoenhagen P, et al. Effect of intensive compared with moderate lipid-lowering therapy on progression of coronary atherosclerosis: A randomized controlled trial. JAMA 2004;291:1071-1080.

12. Bazzano LA, He J, Odgden LG, et al. Fruit and vegetable intake and risk of cardiovascular disease in US adults: The first National Health and Nutrition Examination Survey Epidemiologic Follow-up Study. Am J Clin Nutr 2002; 76:93-99.

13. Datillo AM, Kris-Etherton PM. Effects of weight reduction on blood lipids and lipoproteins: A meta-analysis. Am J Clin Nutr 1992;56:320-328.

14. Tran ZV, Weltman A. Differential effects of exercise on serum lipid and lipoprotein levels seen with changes in body weight. IAMA 1985;254:919-924.

15. Stefanick ML, Mackey S, Sheehan M, Ellsworth N, Haskell WL, Wood PD. Effects of diet and exercise in men and postmenopausal women with low levels of HDL cholesterol and high levels of LDL cholesterol. $\mathrm{N}$ Engl J Med 1998;339:12-20.

16. Butowski PF, Winder AF. Usual care dietary practice, achievement and implications for medication in the management of hypercholesterolaemia. Data from the U.K. Lipid Clinics Programme. Eur Heart J 1998;19:1328-1333.

17. Leon AS, Bronas UG. Dyslipidemia and risk of coronary heart disease: Role of lifestyle approaches for its management. Am J Lifestyle Med 2009;3:257-273.

18. Pearson GJ, Thompson AE, Semchuk W. Guidelines for the management of dyslipidemia and prevention of cardiovascular disease by pharmacists. Can Pharm J 2008;141:S11-S16.

19. Prevention of coronary heart disease in clinical practice. Recommendations of the Second Joint Task Force of European and other Societies on coronary prevention. Eur Heart J 1998;19:1434-1503.

20. Mann DM, Allegrante JP, Natarajan S, Halm EA, Charlson M. Predictors of adherence to statins for primary prevention. Cardiovasc Drugs Ther 2007;21:311-316.

21. Teramoto T, Sasaki J, Ueshima H, et al. Goals of dyslipidemia management. J Atheroscler Thromb 2007:14:209-212.

22. Cannon $\mathrm{CP}$, Braunwald $\mathrm{E}, \mathrm{McCabe} \mathrm{CH}$, et al. Intensive and moderate lipid lowering with statins after acute coronary syndromes. N Eng J Med 2004;350:1495-1504.

23. Heart Protection Study Collaborative Group. MRC/BHF Heart Protection Study of cholesterol lowering with simvastatin in 20,536 high-risk individuals: A randomized placebo-controlled trial. Lancet 2002;360:7-22.

24. Law MR, Wald NJ, Rudnicka AR. Quantifying effect of statins on low density lipoprotein cholesterol, ischaemic heart disease, and stroke: Systematic review and metaanalysis. BMJ 2003;326:1423-1430.

25. Sever PS, Dublof B, Poulter NR, et al. Prevention of coronary and stroke events with atorvastatin in hypertensive patients who have average or lower-than-average cholesterol concentrations, in the Anglo-Scandinavian Cardiac Outcomes Trial-Lipid Lowering Arm (ASCOT-LLA): A muticentre randomized controlled trial. Lancet 2003:361: 1149-1158.

26. Parris ES, Lawrence DB, Mohn LA, Long LB. Adherence to statin therapy and LDL cholesterol goal attainment by patients with diabetes and dyslipidemia. Diabetes Care 2005;28:595-599.

27. LaRosa JC, He J, Vupputuri S. Effect of statins on risk of coronary disease: A meta-analysis of randomized controlled trials. IAMA 1999;282:2340-2346. 
28. Gould AL, Rossouw JE, Santanello NC, Heyse JF, Furberg CD. Cholesterol reduction yields clinical benefit: Impact of statin trials. Circulation 1998;97:946-952.

29. Goldberg KC, Melnyk SD, Simel DL. Overcoming inertia: Improvement in achieving target low-density lipoprotein cholesterol. Am J Manag Care 2007;13:530-534.

30. McBride P, Schrott HG, Plane MB, Underbakke G, Brown RL. Primary care practice adherence to National Cholesterol Education Program guidelines for patients with coronary heart disease. Arch Intern Med 1998;158:12381244.

31. Pearson TA, Laurova I, Chu H, Kafonek S. The Lipid Treatment Assessment Project (L-TAP): A multicenter survey to evaluate the percentages of dyslipidemic patients receiving lipid-lowering therapy and achieving low-density lipoprotein in cholesterol goals. Arch Intern Med 2000; 160:459-467.

32. Sloan KI, Sales AE, Willems JP, et al. Frequency of serum low-density lipoprotein cholesterol measurement and frequency of results $<$ or $=100 \mathrm{mg} / \mathrm{dl}$ among patients who had coronary events (Northwest VA Network Study). Am J Cardiol 2001;88:1143-1146.

33. Ford ES, Mokdad AH, Giles WH, Mensah GA. Serum total cholesterol concentrations and awareness, treatment, and control of hypercholesterolemia among US adults: Findings from the National Health and Nutrition Examination Survey, 1999-2000. Circulation 2003;107:2185-2189.

34. Olson KI, Tsuyuki RT. Patients' achievement of cholesterol targets: A cross-sectional evaluation. Am J Prev Med 2003;25:339-342.

35. Olson KI, Bungard TI, Tsuyuki RT. Cholesterol risk management: A systematic examination of the gap from evidence to practice. Pharmacotherapy 2001;21:807-817.

36. Baessler A, Fischer M, Huf V, et al. Failure to achieve recommended LDL cholesterol levels by suboptimal statin therapy relates to elevated cardiac event rates. Int J Cardiol 2005;101:293-298.

37. Frolkis JP, Pearce GL, Nambi V, Minor S, Sprecher DL. Statins do not meet expectations for lowering low-density lipoprotein cholesterol levels when used in clinical practice. Am J Med 2002;113:625-629.

38. Centers for Disease Control and Prevention. Disparities in screening for and awareness of high blood cholesterolUnited States, 1999-2002. MMWR Morb Mortal Wkly Rep 2005;54:117-119.

39. Nau DP, Mallya U. Sex disparity in the management of dyslipidemia among patients with type 2 diabetes mellitus in a managed care organization. Am J Manag Care 2005;11:69-73.

40. Kontos MC, Joyner SE, Roberts CS, et al. Implications of the new low-density lipoprotein goals in dyslipidemia management of patients with acute coronary syndrome. Mayo Clin Proc 2007:82:551-555.

41. Reiner Z. Combined therapy in the treatment of dyslipidemia. Fundam Clin Pharmacol 2010;24:19-28.

42. Patel JV, Hughes EA. Efficacy, safety and LDL-C goal attainment of ezetimibe $10 \mathrm{mg}$-simvastatin $20 \mathrm{mg}$ vs. placebosimvastatin $20 \mathrm{mg}$ in UK-based adults with coronary heart disease and hypercholesterolaemia. Int J Clin Pract 2006: 60:914-921.

43. Davidson MH, McGarry $T$, Bettis R, et al. Ezetimibe coadministered with simvastatin in patients with primary hypercholesterolemia. I Am Coll Cardiol 2002;40:21252135.
44. Teoh H, Mendelsohn AA, Goodman SG, et al. Usefulness of statin-ezetimibe combination to reduce the care gap in dyslipidemia management in patients with a high risk for atherosclerotic disease. Am J Cardiol 2009;104:798-804.

45. Ballantyne CM, Weiss $\mathrm{R}$, Moccetti $\mathrm{T}$, et al. Efficacy and safety of rosuvastatin $40 \mathrm{mg}$ alone or in combination with ezetimibe in patients at high risk of cardiovascular disease (results from the EXPLORER study). Am J Cardiol 2007; 99:673-680.

46. Kerzner B, Corbelli J, Sharp S, et al. Efficacy and safety of ezetimibe coadministered with lovastatin in primary hypercholesterolemia. Am J Cardiol 2003;91:418-424.

47. Chao J. Improving medication adherence: The role of the health care delivery system and health care providers. J Manag Care Pharm 2007;13:807-809.

48. Sabate E. Adherence to long-term therapies: Evidence for action. Available at: http://www.who.int/chp/knowledge/ publications/adherence_report/en/index.html. Accessed August 2009.

49. Berg JS, Dischler J, Wagner DJ, Raia JJ, Palmer-Shevlin N. Medication compliance: A healthcare problem. Ann Pharmacother 1993;27:1-24.

50. Avorn J, Monette J, Lacour A, et al. Persistence of use of lipid-lowering medications: A cross-national study. IAMA 1998;279:1458-1462.

51. Tsuyuki RT, Bungard TJ. Poor adherence with hypolipidemic drugs: A lost opportunity. Pharmacotherapy 2001;21:576-582.

52. Ye X, Gross Cr, Schommer J, Cline R, St Peter WL. Association between copayment and adherence to statin treatment initiated after coronary heart disease hospitalizations: A longitudinal, retrospective, cohort study. Clin Ther 2007; 29:2748-2757.

53. McGinnis B, Olson KL, Magid D, et al. Factors related to adherence to statin therapy. Ann Pharmacother 2007;41: 1805-1811.

54. Coombs JH, Cornish L, Hiller P, Smith DG. Compliance and refill pattern behavior with HMG-CoA reductase inhibitors after acute myocardial infarction. Manag Care Interface 2002;15:54-58, 60.

55. Batal HA, Krantz MJ, Dale RA, Mehler PS, Steiner JF. Impact of prescription size on statin adherence and cholesterol levels. BMC Health Serv Res 2007;7:175-180.

56. Gibson TB, Mark TL, Axelsen K, Baser O, Rublee DA, McGuigan KA. Impact of statin copayments on adherence and medical care utilization and expenditures. Am J Manag Care 2006;12 Spec no:SP11-SP19.

57. Huskamp HA, Deverka PA, Epstein AM, Epstein RS, McGuigan KA, Frank RG. The effect of incentive-based formularies on prescription-drug utilization and spending. N Engl J Med 2003;349:2224-2232.

58. Goldman DP, Joyce GF, Escarce JJ, et al. Pharmacy benefit and the use of drugs by the chronically ill. JAMA 2004; 291:2344-2350.

59. Pedan A, Varasteh L, Schneeweiss S. Analysis of factors associated with statin adherence in a hierarchical model considering physician, pharmacy, patient, and prescription characteristics. J Manag Care Pharm 2007;13:487-496.

60. Kessler RC, Cantrell CR, Berglund P, Sokol MC. The effects of copayments on medication adherence during the first two years of prescription drug treatment. I Occup Environ Med 2007;49:597-609.

61. Wei L, Macdonald TM, Watson AD, Murphy MJ. Effectiveness of two statin prescribing strategies with respect to 
adherence and cardiovascular outcomes: observational study. Pharmacoepidemiol Drug Safety 2007;16:385-392.

62. McGinnis B, Olson KL, Magid D, et al. Factors related to adherence to statin therapy. Ann Pharmacother 2007; 47:1805-1811.

63. Bodenheimer T. Helping patients improve their healthrelated behaviors: What system changes do we need? Dis Manag 2005;8:319-330.

64. Ho PM, Bryson CL, Rumsfeld JS. Medication adherence: Its importance in cardiovascular outcomes. Circulation 2009;119:3028-3035.

65. Osterberg L, Blaschke T. Adherence to medication. N Engl J Med 2005;353:487-497.

66. Lee TH, Cleeman JI, Grundy SM. Clinical goals and performance measures for cholesterol management in secondary prevention of coronary heart disease. JAMA 2000;283:94-98.

67. Nair KV, Saseen JJ. Quality assessment of dyslipidemia in managed care: Current best evidence should be used to benchmark quality. Ann Pharmacother 2006;40:124-127.

68. Davidson MH. Differences between clinical trial efficacy and real-world effectiveness. Am J Manag Care 2006; 12:S405-S411.

69. Mosca L, Linfante AH, Benjamin EJ, et al. National study of physician awareness and adherence to cardiovascular disease prevention guidelines. Circulation 2005;111:499-510.

70. Rodondi N, Peng T, Karter AJ, et al. Therapy modifications in response to poorly controlled hypertension, dyslipidemia, and diabetes mellitus. Ann Intern Med 2006;144:475484.

71. Pasternak RC, Smith SC, Bairey-Merz CN, Grundy SM, Cleeman JI, Lenfant C. ACC/AHA/NHLBI clinical advisory on the use and safety of statins. Circulation 2002; 106:1024-1028.

72. Ellis JJ, Erickson SR, Stevenson JG. Suboptimal statin adherence and discontinuation in primary and secondary prevention populations: Should we target patients with the most to gain? J Gen Intern Med 2004;19:638-645.

73. Benner JS, Tierce JC, Ballantyne CM, et al. Follow-up lipid tests and physician visits are associated with improved adherence to statin therapy. Pharmacoeconomics 2004;22: 13-23.

74. Cutler TW, Palmieri J, Khalsa M, Stebbins M. Evaluation of the relationship between a chronic disease care management program and California pay-for-performance diabetes care cholesterol measures in one medical group. J Manag Care Pharm 2007;13:578-588.

75. Maviglia SM, Teich JM, Fiskio J, Bates DW. Using an electronic medical record to identify opportunities to improve compliance with cholesterol guidelines. J Gen Intern Med 2001;16:531-537.

76. Kinn JW, O'Toole MF, Rowley SM, Marek JC, Bufalino VJ, Brown AS. Effectiveness of the electronic medical record in cholesterol management in patients with coronary artery disease (Virtual Lipid Clinic). Am J Cardiol 2001;88:163-165.

77. Ginsberg HN, Kris-Etherton $\mathrm{P}$, Dennis B, et al. Effects of reducing dietary saturated fatty acids on plasma lipids and lipoproteins in healthy subjects: The DELTA Study, protocol 1. Arterioscler Thromb Vasc Biol 1998;18:441-449.

78. Schaefer EJ, Lichtenstein AH, Lamon-Fava S, et al. Efficacy of a National Cholesterol Education Program Step 2 diet in normolipidemic and hypercholesterolemic middle-aged and elderly men and women. Arterioscler Thromb Vasc Biol 1995;15:1079-1085.
79. DeBusk RF, Miller NH, Superko HR, et al. A case-management system for coronary risk factor modification after acute myocardial infarction. Ann Intern Med 1994;120:721-729.

80. Haskell WL, Alderman EL, Fair JM, et al. Effects of intensive multiple risk factor reduction on coronary atherosclerosis and clinical cardiac events in men and women with coronary artery disease. The Stanford Coronary Risk Intervention Project (SCRIP). Circulation 1994;89:975-990.

81. Marrs JC. Pharmacy perspectives in dyslipidemia management: Strategies for improving patient outcomes. US Pharmacist 2010;35:3-18.

82. Machado M, Nassor N, Bajcar JM, Guzzo GC, Einarson TR. Sensitivity of patient outcomes to pharmacist interventions. Part III: Systematic review and meta-analysis in hyperlipidemia management. Ann Pharmacother 2008;42:11951207.

83. O'Donnell DC, Chen NT, Piziak VK. Goal attainment and maintenance of serum cholesterol level in a pharmacistcoordinated lipid clinic. Am J Health Syst Pharm 2001; 58:325-330.

84. Collins C, Kramer A, O'Day ME, Low MB. Evaluation of patient and provider satisfaction with a pharmacistmanaged lipid clinic in a Veterans Affairs medical center. Am J Health Syst Pharm 2008;65:2237-2243.

85. Evangelista LS, Dracup K. A closer look at compliance research in heart failure patients in the last decade. Prog Cardiovasc Nurs 2000;15:97-103.

86. Petrilla AA, Benner JS, Battleman DS, Tierce JC, Hazard EH. Evidence-based interventions to improve patient compliance with antihypertensive and lipid-lowering medication. Int J Clin Pract 2005;59:1441-1451.

87. De Geest S, Renteln-Kruse W, Steeman E, Degraeve S, Abraham IL. Compliance issues with the geriatric population: Complexity with aging. Nurs Clin North Am 1998; 33:467-480.

88. Albert NM. Improving medication adherence in chronic cardiovascular disease. Crit Care Nurse 2008;28:54-64.

89. Becker DM, Raqueno JV, Yook RM, et al. Nurse-mediated cholesterol management compared with enhanced primary care in siblings of individuals with premature coronary disease. Arch Intern Med 1998;158:1533-1539.

90. Levensky ER, Forcehimes A, O'Donohue WT, Beitz K. Motivational interviewing: An evidence-based approach to counseling helps patients follow treatment recommendations. Am J Nurs 2007;107:50-58.

91. Stafford RS, Radley DC. The potential of pill splitting to achieve cost savings. Am J Manag Care 2002;8:706-712.

92. Carr-Lopez SM, Mallett MS, Morse T. The tablet splitter: Barrier to compliance or cost-saving instrument? Am J Health Syst Pharm 1995;52:2707-2708.

93. Fawell NG, Cookson TL, Scranton SS. Relationship between tablet splitting and compliance, drug acquisition cost, and patient acceptance. Am J Health Syst Pharm 1999;56:2542-2545.

94. Gee M, Hasson NK, Hahn T, et al. Effects of a tabletsplitting program in patients taking HMG-CoA reductase inhibitors: Analysis of clinical effects, patient satisfaction, compliance, and cost avoidance. J Manag Care Pharm 2002;8:453-458.

95. Bachynsky J, Wiens C, Melnychuk K. The practice of splitting tablets-Cost and therapeutic aspects. Pharmacoeconomics 2002;20:339-346.

96. McDevitt JT, Gurst AH, Chen Y. Accuracy of tablet splitting. Pharmacotherapy 1998;18:193-197. 
97. Choe HM, Stevenson JG, Streetman DS, Heisler M, Sanford CJ, Piette JD. Impact of financial incentives on participation and outcomes in a statin pill-splitting program. Am J Manag Care 2007;13:298-304.

98. Kaufman MB. Electronic medication management system available to improve medication adherence. Formulary 2008;43:223.

99. Rosen MI, Ryan C, Rigsby M. Motivational enhancement and MEMS review to improve medication adherence. Behav Change 2002;19:183-190.

100. Fendrick AM, Smith DG, Chernew ME, et al. A benefitbased copay: Patient contribution based on total benefits, not drug acquisition cost. Am J Manag Care 2001;7:861867.

101. Thiebaud P, Patel BV, Nichol MB. The demand for statin: The effect of copay on utilization and compliance. Health Econ 2008;17:83-97.

102. Chernew ME, Shah MR, Wegh A, et al. Impact of decreasing copayments on medication adherence within a disease management environment. Health Affairs (Millwood) 2008;27:103-112.

103. Sokol MC, McGuigan KA, Verbrugge RR, Epstein RS. Impact of medication adherence on hospitalization risk and healthcare cost. Med Care 2005;43:521-530.

104. Bunting BA, Smith BH, Sutherland SE. The Asheville Project: Clinical and economic outcomes of a communitybased long-term medication therapy management program for hypertension and dyslipidemia. J Am Pharm Assoc 2008;48:23-31

105. Tsuyuki RT, Johnson JA, Teo KK, et al. A randomized trial of the effect of community pharmacist intervention on cholesterol risk management: The Study of Cardiovascular
Risk Interventions by Pharmacists (SCRIP). Arch Intern Med 2002;162:1149-1155.

106. Burton WN, Chen CY, Schultz AB, Edington DW. The association between achieving low-density lipoprotein cholesterol (LDL-C) goal and statin treatment in an employee population. Popul Health Manag 2010;13:1-8.

107. Bloch MJ, Armstrong DS, Dettling L, Hardy A, Caterino K, Barrie S. Partners in lowering cholesterol: Comparison of a multidisciplinary educational program, monetary incentives, or usual care in the treatment of dyslipidemia identified among employees. I Occup Environ Med 2006;48: 675-681.

108. Goldman DP, Joyce GF, Zheng Y. Prescription drug sharing: Associations with medication and medical utilization and spending and health. JAMA 2007;298:61-69.

109. Schedlbauer A, Schroeder K, Peters TJ, Fahey T. Interventions to improve adherence to lipid lowering medication. Cochrane Database Syst Rev 2004;:CD004371.

110. Afonso NM, Nassif G, Aranha ANF, DeLor B, Cardozo LJ. Low-density lipoprotein cholesterol goal attainment among high-risk patients: Does a combined intervention targeting patients and providers work? Am J Manag Care 2006; 12:589-594.

Address correspondence to: Alyssa B. Schultz, Ph.D.

University of Michigan Health Management Research Center 1015 E. Huron Street Ann Arbor, MI 48104-1688

E-mail: abelaire@umich.edu 